\title{
Determination of gamma-hydroxybutyric acid in biofluids using a one-step procedure with "in-vial" derivatization and headspace-trap gas chromatography-mass spectrometry
}

\author{
Ann-Sofie ME Ingels ${ }^{\text {as }}$, Hugo Neels ${ }^{b, c}$, Willy E Lambert ${ }^{a}$, Christophe P Stove ${ }^{a *}$ \\ a'Laboratory of Toxicology, Ghent University, Harelbekestraat 72, 9000 Ghent, Belgium \\ ${ }^{b}$ Laboratory of Toxicology, Antwerp University, Drie eiken Campus, 2000 Antwerp, Belgium \\ 'Laboratory of Toxicology, ZNA Stuivenberg Hospital, Lange Beeldekensstraat 267, 2030 Antwerp, Belgium

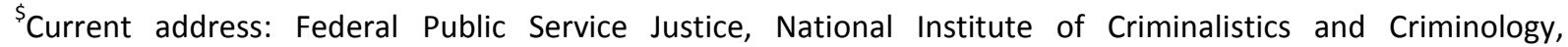 \\ Vilvoordsesteenweg 100, 1120 Brussels, Belgium
}

\section{http://dx.doi.org/10.1016/j.chroma.2013.04.023}

\footnotetext{
* Corresponding author
}

Laboratory of Toxicology

Faculty of Pharmaceutical Sciences

Harelbekestraat 72

9000 Ghent

Belgium

Tel. 0032.9.264.81.36

Fax 0032.9.264.81.83

E-mail: Christophe.stove@ugent.be 


\section{Abstract}

A headspace-trap gas chromatography-mass spectrometry (HS-trap GC-MS) method was developed to determine GHB, a low molecular weight compound and drug of abuse, in various biological fluids. Combining this relatively novel and fully automated headspace technique with "in-vial" methylation of GHB allowed for a straightforward approach. One single method could be used for all biofluids (urine, plasma, serum, whole blood or lyzed blood), requiring only $100 \mu$ of sample. Moreover, our approach involves mere addition of all reagents and sample into one vial. Following optimization of headspace conditions and trap settings, validation was performed. Although sample preparation only consists of the addition of salt and derivatization reagents directly to a $100 \mu \mathrm{l}$-sample in a HS-vial, adequate method sensitivity and selectivity was obtained. Calibration curves ranged from 5 to $150 \mu \mathrm{g} / \mathrm{ml} \mathrm{GHB}$ for urine, from 2 to $150 \mu \mathrm{g} / \mathrm{ml}$ for plasma, and from 3.5 to $200 \mu \mathrm{g} / \mathrm{ml}$ for whole blood. Acceptable precision and accuracy (<13\% bias and imprecision) was seen for all quality controls (QC's) (LLOQ-level, low, medium, high), including for the supplementary serum- and lyzed blood-based QC's, using calibration curves prepared in plasma or whole blood, respectively. Incurred sample reanalysis demonstrated assay reproducibility, while cross-validation with another GC-MS method demonstrated that our method is a valuable alternative for GHB determination in toxicological samples, with the advantage of requiring only $100 \mu \mathrm{l}$ and minimal hands-on time, as sample preparation is easy and injection automated.

\section{Keywords}

Gamma-hydroxybutyric acid (GHB), in-vial derivatization, gas chromatography coupled to mass spectrometry (GC-MS), headspace-trap (HS-trap), biological matrices, toxicology 


\section{Introduction}

In numerous analytical methods to detect and quantify drugs in biological matrices, sample preparation is regarded as the most laborious and time-consuming step [1,2]. Hence, a tendency towards less demanding procedures has been noted, such as automated solid phase extraction (SPE), dilution or filtration of the samples prior to injection, thereby reducing manual operations, often with a simultaneous reduction of the initial sample size [1,2]. Moreover, if the analytes of interest are volatile enough, headspace (HS) extraction techniques can be used as these combine extraction and injection in a single step. Only relatively recently, a new HS technique has been commercialized: HS-trap, encompassing an enhanced static headspace system covering both static and dynamic HS properties. This technique, already successfully applied to determine various volatile compounds in water [3], spirits [4], soil [5], apple juices [6] and plant matrices [7], was evaluated for its possibility to determine gamma-hydroxybutyric acid (GHB), a low molecular weight compound and drug of abuse, in biofluids such as urine, plasma, serum and whole blood. Detection and quantification of GHB in biological matrices is of interest in toxicological cases, since recreational use with limited awareness of the possibility to suddenly fall into a coma has resulted in an increase in GHB intoxications at raves or other dance parties [8,9]. Reported procedures, mostly using gas chromatography (GC) -although liquid chromatography (LC) and capillary zone electrophoresis have been applied as well- often include laborious sample preparation steps. While in a UHPLC-MS/MS method mere filtration and dilution prior to injection was shown to suffice as sample preparation for urine samples, extraction with SPE was required for whole blood samples [10]. For GC analysis, either derivatization to a more volatile derivative or conversion to the more volatile lactone-form gamma-butyrolactone (GBL) is required [11]. Several options have been described that allow to reduce the work-load associated with GC-MS-based GHB determination in biological fluids. These include the addition of excess derivatization reagents directly to biological samples, thus omitting the extraction step [12-15], the use of HS injection after conversion of GHB to gamma-butyrolactone (GBL) [16-18] or "in-vial" derivatization with for example hexylchloroformate prior to solid-phase microextraction (SPME) [19] or HS injection [20]. The available HS-based methods, either 'classical' static HS [16], SPME [17,20], or solidphase dynamic extraction (SPDE) [18], all start from 0.5-1 $\mathrm{ml}$ of biofluid (water, urine, plasma, serum or whole blood), providing sufficient sensitivity (LLOQ from 0.1 to $5.0 \mu \mathrm{g} / \mathrm{ml}$ ). In this study, we evaluated whether the combination of two advantageous options, "in-vial" derivatization/conversion and headspace injection, may 
represent a valuable alternative for existing methods. A third advantage is that smaller sample volumes may be analyzed, while still providing enough sensitivity. This is because, when compared to SPME or SPDE, the trap described here allows sampling of a larger headspace fraction, since its adsorptive capacity (having a solid sorbent volume of $160 \mathrm{~mm}^{3}$ ) is much larger than that of the small fibers or coated capillaries (having volumes of 0.94-5.99 $\mathrm{mm}^{3}$ ) used in SPME or SPDE [4]. Furthermore, by combining "in-vial" derivatization and HS-trap, the application range can be extended to non-volatile analytes, with a negligible increase in workload [21]. Thus, the aim of this study was to develop a HS-trap GC-MS procedure to determine GHB in a small sample volume $(100 \mu \mathrm{l})$ of biofluids with minimal sample handling: sample handling is limited to the addition of a sample and reagents to a single vial, followed by closing the vial. Method validation was performed and applicability was demonstrated by analysis of samples from suspected GHB-intoxicated patients.

\section{Materials and methods}

\subsection{Chemicals and reagents}

Na-GHB and its internal standard (IS) Na-GHB-d6 were supplied by LGC standards (Molsheim, France). Dimethyl sulphate (DMS) and tetrabutylammonium-hydrogensulphate $\left(\mathrm{TBA}^{\mathrm{H}} \mathrm{HSO}_{4}\right)$ were delivered by Sigma-Aldrich (Steinheim, Germany), while anhydrous sodium sulphate $\left(\mathrm{Na}_{2} \mathrm{SO}_{4}\right)$ and methanol $(\mathrm{MeOH})$ of analytical grade were supplied by Merck (Darmstadt, Germany). Sodium hydroxide ( $\mathrm{NaOH}$ ) was supplied by VWR (Stockholm, Sweden). Ultrapure water from a Synergy ultrapure water purification system (Millipore, Brussels, Belgium) was used in the experiments.

\subsection{Preparation of stock and working solutions}

A $10 \mathrm{mg} / \mathrm{ml}$ stock solution of GHB was prepared by dissolving 12,2 mg Na-GHB powder in $1 \mathrm{ml}$ MeOH. Working solutions of $\mathrm{GHB}$ of 1 and $0.1 \mathrm{mg} / \mathrm{ml}$ were prepared by appropriate dilution of the stock solution in $\mathrm{MeOH}$. From a second, separately prepared $10 \mathrm{mg} / \mathrm{ml}$ stock solution of GHB, 1 and $0.1 \mathrm{mg} / \mathrm{ml}$ working solutions were prepared for quality control (QC) samples. 
Similar to the preparation of the GHB stock solutions, a $10 \mathrm{mg} / \mathrm{ml}$ stock solution of GHB-d6 was prepared in $\mathrm{MeOH}$. By appropriate dilution of this stock solution in water, a $0.30 \mathrm{mg} / \mathrm{ml} \mathrm{GHB}-\mathrm{d} 6$ working solution was freshly prepared each week or as needed, and stored at $-20^{\circ} \mathrm{C}$.

\subsection{Headspace-trap settings}

A PerkinElmer Turbomatrix HS-40 trap automatic headspace sampler with trap enrichment (Shelton, CT, USA) was used. The principle of the HS-trap method has been illustrated by Barani et al. [22] and Schulz et al. [4]. A brief description of the procedure is given below. A vial is heated, and when the analytes reach equilibrium between headspace and sample matrix, an aliquot of the headspace is withdrawn. To this end, the vial is pressurized, followed by trap loading until the pressure in the HS vial reaches atmospheric pressure. The trap is maintained at lower temperature, just above ambient, leading to condensation of the gaseous phase, while water can be removed by purging helium through the trap. Then, the trap is heated and backflushed, leading to desorption of the analytes that enter the chromatographic system [3].

A Tenax ${ }^{\mathrm{TM}}$ trap, containing the porous polymer 2,6-diphenyl oxide, was used in all experiments and was delivered by Perkin Elmer (Shelton, CT, USA), as well as $22 \mathrm{ml}$ vials with polytetrafluoroethylene (PTFE)/silicone septa. HS vials were used once, as recommended by the manufacturer; the derivatization reagent required caution and proper sample handling and waste removal [23]. The HS oven can thermostat several vials at the same time, the period from injection to injection was automatically calculated by the HS system and was set at $30 \mathrm{~min}$.

HS-trap conditions were optimized to determine GHB in urine, plasma and whole blood. To optimize trap parameters and vial pressure and pressurization time, water samples spiked with GHB were analyzed. Other parameters were optimized using spiked biofluids, as described below and more into detail in the results and discussion section.

\subsubsection{Effect of salting out}

The effect of adding anhydrous $\mathrm{Na}_{2} \mathrm{SO}_{4}$ to the sample matrix was evaluated by analyzing samples with increasing amounts of salt. Therefore, to $100 \mu \mathrm{l}$ of biofluid spiked with 10 (urine) or 25 (plasma and whole blood) $\mu \mathrm{g} / \mathrm{ml} \mathrm{GHB}$, no salt, 50, 100, 120 or $150 \mathrm{mg} \mathrm{Na}_{2} \mathrm{SO}_{4}(\mathrm{n}=3)$ was added. Fifteen $\mu$ l of a 5-M NaOH solution 
and $30 \mu \mathrm{l}$ DMS were added to derivatize GHB to its corresponding di-methyl derivative. The vials were closed immediately and analyzed within $24 \mathrm{~h}$. Resulting peak areas of GHB were compared ( $\mathrm{n}=3$ for each condition) and significance of differences was checked at 0.05 significance level using one-way ANOVA with post hoc Bonferroni correction.

\subsubsection{Equilibration time and temperature}

To determine the equilibration time, $100 \mu$ of biofluid was spiked with $25 \mu \mathrm{g} / \mathrm{ml} \mathrm{GHB}$; 100 or 50 mg (whole blood) $\mathrm{Na}_{2} \mathrm{SO}_{4}, 15 \mu \mathrm{l} \mathrm{NaOH} 5 \mathrm{M}$ and $30 \mu \mathrm{l}$ DMS were added and the HS vial was closed. Analysis was performed in triplicate and the time to reach equilibrium was varied from 10 to $60 \mathrm{~min}$. The resulting peak areas of GHB were plotted in function of time; when the signal reaches a plateau, this indicates that equilibrium is reached [24].

\subsection{GC-MS analysis}

The HS-trap was connected to a 6890 Agilent gas chromatographic system and a 5973 mass spectrometer (Agilent, Avondale, PA, USA). The GC-MS procedure was optimized to selectively determine GHB in biofluids using HS-trap as injection technique. A DB-624 (30m x $0.25 \mathrm{~mm}$ ID $\times 1.4 \mu \mathrm{m}$ film thickness) (Agilent, Avondale, PA, USA) analytical column was chosen. The HS transfer line was directly coupled to the analytical column using a butt connector, and was maintained at $150^{\circ} \mathrm{C}$, as recommended by the manufacturer, to avoid condensation on possible cold spots [3]. Helium was used as carrier gas, at constant column inlet pressure of 15 psi. The GC temperature program started at $40{ }^{\circ} \mathrm{C}$, which was maintained for $2 \mathrm{~min}$, then ramped at $10{ }^{\circ} \mathrm{C} / \mathrm{min}$ to $170{ }^{\circ} \mathrm{C}$, resulting in a total run time of $15 \mathrm{~min}$. Solvent delay was set at $9 \mathrm{~min}$, and derivatized GHB-d6 and GHB eluted at 11.82 and $11.88 \mathrm{~min}$, respectively.

The mass spectrometer operated in the electron impact (EI) mode with ionization energy of $70 \mathrm{eV}$. The transfer line temperature was set at $210{ }^{\circ} \mathrm{C}$, the ion source at $230{ }^{\circ} \mathrm{C}$, and the quadrupole temperature at $150{ }^{\circ} \mathrm{C}$. Following the initial acquisition of the mass spectra in SCAN mode, selective $m / z$ fragments were selected of derivatized GHB and its IS. For GHB quantification in various biological matrices, the mass spectrometer operated in the selected ion monitoring (SIM) mode. The following $\mathrm{m} / \mathrm{z}$ ions were chosen for GHB: $117, \underline{101}, 74$ and 59; and for GHB-d6: 123, 107, 77 and 63. Underscored ions represent quantifier ions, which are not the most abundant but the most selective for GHB and GHB-d6. As GHB is a low molecular weight compound, and 
methylation does not result in the formation of high mass fragments, quantifier and qualifier ions were not chosen based on relative intensities, but on being selective for GHB and GHB-d6 (Fig 5d) [13]. Data acquisition and integration were carried out with Chemstation software MSDChem (Agilent, Avondale, PA, USA).

\section{5 "In-vial" derivatization}

The "in-vial" derivatization is a modification of the procedure recently published by Rasanen et al. [23]. Briefly, different volumes of the methylation reagent DMS, $5 \mathrm{M} \mathrm{NaOH}$ and TBA-HSO $(0.1 \mathrm{M})$, were added to $0.1 \mathrm{ml}$ of sample. $\mathrm{TBA}^{-} \mathrm{HSO}_{4}$ is an ion pairing agent, which may activate the analytes during derivatization, thereby increasing esterification yields, thus improving the sensitivity of a derivatization procedure. Preliminary experiments in water and biofluids showed no improvement of derivatization and extraction yield of GHB using the ion-pairing agent (data not shown), so $\mathrm{TBA}^{-} \mathrm{HSO}_{4}$ was no longer added to a $\mathrm{HS}$ vial during further experiments. Furthermore, during further optimization (see 3.1 "In-vial" derivatization), we evaluated various volumes of $\mathrm{NaOH}(15,30$ and $60 \mu \mathrm{l})$. To this end, we spiked $100 \mu \mathrm{l}$ of urine, plasma and whole blood with 25 $\mu \mathrm{g} / \mathrm{ml} \mathrm{GHB}$ and compared the resulting peak areas of GHB (mean \pm st $\mathrm{dev}, \mathrm{n}=3$ ).

\subsection{Sample preparation}

One hundred $\mu \mathrm{l}$ sample was added to a $22 \mathrm{ml} \mathrm{HS}$ vial. Ten $\mu \mathrm{l}$ of a $0.30 \mathrm{mg} / \mathrm{ml}$ solution in water of the IS GHB-d6 was added, followed by addition of $100 \mathrm{mg}$ anhydrous $\mathrm{Na}_{2} \mathrm{SO}_{4}, 30 \mu \mathrm{l} 5 \mathrm{M} \mathrm{NaOH}$ and $30 \mu \mathrm{LMS}$. The vial was properly sealed and in the case of whole blood and plasma, samples were vortexed for 10 sec before placing the vial in the HS autosampler. To conduct method development and validation, healthy drug-free volunteers donated EDTA-anticoagulated whole blood and urine.

\subsection{Analytical performance and application}

The analytical performance of the optimized method was evaluated based on guidelines of the European Medicines Agency (EMA) for validation of bioanalytical methods [25]. To determine inter- and intra-batch precision, QC's (LLOQ, low, medium, high, $2 \times$ ULOQ) were analyzed in duplicate on 4 different days, and precision was calculated using one-way ANOVA [26]. Accuracy (\% bias) was determined by dividing the difference between the measured mean and the nominal value by the nominal value and multiplying it with $100 \%$. Bias and imprecision should be $<15 \%$ for all QC's, except at LLOQ, where it should be $<20 \%$ [25]. To 
evaluate if plasma calibrators can be used for quantification of GHB in serum samples, QC samples prepared in serum were also measured together with calibration samples prepared in plasma. Similarly, to evaluate if calibrators prepared in whole blood are suitable for quantification of GHB in lyzed blood samples such as postmortem whole blood samples, QC samples were prepared in fresh whole blood (stored for a maximum of 7 days at $4{ }^{\circ} \mathrm{C}$ after collection) and lyzed blood (submitted to 2 freeze-thaw cycles before spiking). Also linearity, sensitivity, stability of processed samples, selectivity and carry-over were evaluated, as described more into detail below (3.5 Analytical performance). It was defined that no carry-over was seen if in a blank sample injected after a $200 \mu \mathrm{g} / \mathrm{ml} \mathrm{GHB}$ water sample, the area at the retention time of GHB was $<20 \%$ of the area of the LLOQ [25].

The applicability of the HS-trap injection technique was demonstrated using patient samples. To this end, we analyzed urine and serum samples (anonymous leftovers) from suspected GHB-intoxicated patients, kindly provided by the Laboratory of Toxicology of Ghent University Hospital and by the AZ St-Jan Hospital in Bruges, and a whole blood sample received in our own Laboratory. To evaluate assay reproducibility, incurred sample reanalysis (ISR) was performed after a minimum of 7 days of storage at $-20{ }^{\circ} \mathrm{C}$. The initial concentration and that obtained by reanalysis should be within $20 \%$ of their mean for at least $67 \%$ of the repeats [25]. Furthermore, for method comparison, we performed a cross-validation by analyzing an aliquot of the samples at the Laboratory of Toxicology of ZNA Stuivenberg Hospital in Antwerp, using the method of Van hee et al. [12]. The difference between the result obtained by the newly developed HS-trap method and that obtained by the previously published method for the determination of GHB should be within $20 \%$ of the mean for at least $67 \%$ of the samples [25].

\section{Results and discussion}

\section{1 "In-vial" derivatization}

Using HS injection techniques, only volatile compounds will partition between the sample matrix and the headspace. Consequently, an aliquot of the sample can be brought directly into the HS vial, requiring a minimum of sample preparation [24]. "In-vial" or "in-situ" derivatization techniques are compatible with this general advantage and were evaluated for GHB derivatization in biofluids. In literature, "in-situ" 
hexylchloroformation of GHB has been reported in urine samples, followed by SPME [19,20]. However, when applying this derivatization reagent to water samples spiked with GHB, we had difficulties to desorb hexyl-GHB from the trap (preliminary results, data not shown). Furthermore, only two fragments were formed using the MS in El mode, requiring background substraction to properly identify the presence of hexyl-GHB. Therefore, methylation was considered, as also used by Rasanen et al. [23] for "in-vial" derivatization of hydroxylic analytes, including GHB, in urine and extracted blood samples. Safety measures should be taken into account, and excess reagent should be avoided, as it can enter the gaseous phase and interfere with the chromatographic detection of di-methyl GHB [27]. We evaluated this "in-vial" methylation reaction on $100 \mu$ l of urine, plasma and whole blood, spiked at $25 \mu \mathrm{g} / \mathrm{ml} \mathrm{GHB}$. Comparison of the resulting peak areas of derivatized GHB led us to choose a 1:1 ratio of $\mathrm{NaOH}(5 \mathrm{M})$ and DMS (30 $\mu$ l for both) in the final procedure (Fig. 1).

\subsection{Effect of salting out}

Adding salt to a HS vial may decrease analyte solubility in a water-based matrix and result in an additional volume-effect, facilitating the transfer of the analyte from the sample matrix to the headspace [24]. As shown in Fig. 2, the addition of salt indeed increased the amount of derivatized GHB in the vapour phase, the difference between no salt and salt added being significant in all matrices, with no significant difference between the different salt concentrations added (one-way ANOVA with Bonferroni correction, $\alpha=0.05, n=3$ ). Based upon these results, we opted to add $100 \mathrm{mg}\left( \pm 5 \mathrm{mg}\right.$ ) of anhydrous $\mathrm{Na}_{2} \mathrm{SO}_{4}$ to each $\mathrm{HS}$ vial in the final procedure.

\subsection{Trap settings}

Trap parameters (overview Table 1) such as trap temperature during trap load and trap desorption were optimized to retain the analytes of interest and to maximize sample transfer to the GC-MS system [4]. In addition, when dealing with aqueous matrices, water removal prior to GC-MS analysis needs special consideration. The latter was achieved by dry purging the trap between its loading and desorption [3]. Conditions of the dry purging step were selected to obtain a maximum of water loss accompanied by a minimum of analyte loss from the trap [4]. For $100 \mu \mathrm{l}$ water samples thermostatted for 50 min at $90{ }^{\circ} \mathrm{C}$, a dry purge time of $10 \mathrm{~min}$ at a trap low temperature of $50{ }^{\circ} \mathrm{C}$ was required to efficiently remove water from the trap. To evaluate possible losses during this drying step, we compared the extraction yields obtained under these 
conditions with those obtained by a 5 min dry purge at $40{ }^{\circ} \mathrm{C}$, the latter being associated with incomplete drying of the trap (as measured by following $\mathrm{m} / \mathrm{z} \mathrm{18}$, corresponding to $\mathrm{H}_{2} \mathrm{O}$ ). Comparing the means of the resulting peak areas using a t-test revealed no significant difference at the 0.05 significance level $(n=3$; relative standard deviations or RSDs < $3 \%$ ) [3].

A well-known point of attention with any trapping technique is the potential of carry-over between samples. To prevent this, complete desorption of analytes from the trap is required [3]. We could minimize carry-over by setting a trap high temperature of $265^{\circ} \mathrm{C}$, desorption time of $2 \mathrm{~min}$ at a pressure of $30 \mathrm{psi}$, and a trap hold time of $10 \mathrm{~min}$. This was evaluated by injecting a $200 \mu \mathrm{g} / \mathrm{ml} \mathrm{GHB}$ spiked water sample, followed by injection of 3 blank water samples. Carry-over was no longer seen after injection of one blank sample following injection of the high concentrated GHB sample. Furthermore, analysis of blank water samples following injection of the highest calibrator prepared in matrix (urine, plasma and whole blood) also demonstrated lack of carry-over in the $2^{\text {nd }}$ blank sample. Higher trap temperatures and higher desorption pressures are not recommended for routine practice, respectively to extend trap life-time and to efficiently remove water during analysis (the same pressure is also used during dry purge, negatively influencing water removal with higher pressures) [3]. Therefore, since carry-over could not be excluded completely using these mild trap settings, blank samples were analyzed between higher concentrated samples. Also, the trap can be re-used for at least 500 injections and if upon progressive use, carry-over would be seen between samples, it can be re-conditioned by heating it at $280{ }^{\circ} \mathrm{C}$ for 30 to $60 \mathrm{~min}$.

\subsection{Headspace conditions}

\subsubsection{Equilibration time and temperature}

Preferably, an aliquot of the vapour phase is sampled when the analytes of interest have reached equilibrium between the sample matrix and the vapour phase. The time needed to reach equilibrium depends on the sample volume, the properties of the analyte of interest and the oven temperature [24]. Preliminary experiments showed that oven temperatures of $70^{\circ} \mathrm{C}$ or lower resulted in a low GHB signal (data not shown). Since the matrices of interest are water-based, the HS oven temperature may not exceed $100{ }^{\circ} \mathrm{C}$. Therefore, $90{ }^{\circ} \mathrm{C}$ was selected for further experiments. Plotting the resulting peak areas of GHB in function of equilibration time at $90{ }^{\circ} \mathrm{C}$, as presented in Fig. 3, shows that the di-methyl derivative of GHB reaches equilibrium after 20-25 
minutes in $100 \mu$ urine, plasma and whole blood. For maximum sample throughput, the period from injection to injection should be as short as possible. The latter is calculated by the instrument, based on the optimized HS parameters. For the determination of GHB in biofluids, this calculation resulted in a minimum interval of 30 min between injections. Therefore, an equilibration time of $30 \mathrm{~min}$ was set, being slightly longer than the minimum required equilibration times of 20 or $25 \mathrm{~min}$.

\subsubsection{Sample shaking}

Shaking of the sample vial during thermostatting may reduce the time needed to reach equilibrium [24]. However, for derivatized GHB no reduction in equilibration time was seen, with shaking rather introducing more variation (supplementary file 1). Consequently, samples were not shaken during further experiments.

\subsubsection{Vial pressure, vial pressurization time and decay time}

The vial pressure was optimized to give the highest sample transfer onto the trap, without risk of vial leakage at the septum or septum puncture [3]. Vial pressure was varied from 20 to 35 psi. An increase in vial pressure from 20 to 30 psi resulted in an approximate $14 \%$ increase in GHB peak area $(n=3)$. A pressure of 35 psi gave lower peak areas (approximate $50 \%$ decrease in peak area, $n=3$ ). Subsequently, vial pressurization time was varied from 1 to $3 \mathrm{~min}$ for a vial pressure of 20 and $30 \mathrm{psi}$ and it was seen that vial pressurization for 1 or $2 \mathrm{~min}$ at 30 psi gave highest peak areas with the lowest RSDs $(<1 \%, n=3)$. Therefore, 1 min vial pressurization with 30 psi was chosen. Decay time or the time needed to decrease the vial pressure to atmospheric pressure after vial pressurization, was calibrated using a blank sample and was set to $1.2 \mathrm{~min}$ [3].

\subsubsection{Repeated vial extraction}

Vial pressurization followed by trap load can be repeated up to 4 times, to almost completely extract the vapour phase of the HS vial (pulse extraction). On the other hand, with each successive extraction, a larger amount of water vapour is introduced on the trap, possibly requiring adjustment of the dry purge step and prolonging analysis time. Furthermore, higher variation in measurement may be seen if equilibrium is no longer reached [3]. For $100 \mu \mathrm{l}$ urine and plasma samples spiked at 10 and $5 \mu \mathrm{g} / \mathrm{ml} \mathrm{GHB}$, respectively, the mean GHB peak area $(n=3)$ increased with approximately $75 \%$ using a second extraction, with acceptable RSDs $(<5 \%)$. A second extraction of $100 \mu \mathrm{l}$ whole blood samples spiked at $5 \mu \mathrm{g} / \mathrm{ml} \mathrm{GHB}$, resulted in a $34 \%$ mean increase of 
the peak area of GHB, as compared to a single vial extraction (Fig. 4). Despite the increase in GHB peak area observed with a second vial extraction, we opted for a single vial extraction since that already resulted in sufficient sensitivity. However, it should be noted that two cycles can be used if lower detection limits would be desired.

\subsection{Analytical performance}

The resulting optimized HS-trap GC-MS method was validated based on EMA guidelines [25] to determine GHB in biofluids: to $100 \mu \mathrm{l}$ sample, $10 \mu \mathrm{l} 0.25 \mathrm{mg} / \mathrm{ml} \mathrm{GHB}-\mathrm{d} 6,100 \mathrm{mg}$ anhydrous $\mathrm{Na}_{2} \mathrm{SO}_{4}, 30 \mu \mathrm{l} 5 \mathrm{M} \mathrm{NaOH}$ and $30 \mu \mathrm{l}$ DMS were added. Subsequently, the vial was properly sealed and placed in the HS autosampler. The sample was equilibrated for $30 \mathrm{~min}$ at $90^{\circ} \mathrm{C}$, before transferring an aliquot of the HS to the Tenax trap $\left(50^{\circ} \mathrm{C}\right.$ ) after vial pressurization (30 psi for $1 \mathrm{~min}$ ). Water was removed during dry purge (30 psi for $10 \mathrm{~min}$ ), followed by desorption (30 psi for 2 min) of di-methylated GHB by heating the trap ( $265^{\circ} \mathrm{C}$ ). The GC-MS operated in SIM mode for GHB quantification.

\section{$\underline{3.5 .1 \text { Selectivity }}$}

To evaluate selectivity, 6 different sources were analyzed for each matrix (urine, plasma, serum and whole blood). Blank (GHB-free) matrices are unavailable since GHB is naturally present in biofluids, and small elevations of $\mathrm{m} / \mathrm{z}$ ions $59,74,101$ and 117 at the retention time of GHB were sometimes seen when analyzing these non-spiked samples. To evaluate the interference of matrix compounds and structural analogues such as beta-hydroxybutyric acid, alpha-hydroxybutyric acid, gamma-aminobutyric acid, 1,4-butanediol, ethyleneglycol, diethyleneglycol, glycolic acid, lactic acid, ureum (urine samples), succinic semi-aldehyde and hydroxy-isovaleric acid, the latter compounds were spiked at $100 \mu \mathrm{g} / \mathrm{ml}$, together with GHB at $10 \mu \mathrm{g} / \mathrm{ml}$ (urine) or $5 \mu \mathrm{g} / \mathrm{ml}$ (plasma, serum and whole blood) and GHB-d6, and analysis was performed as described above ( $\mathrm{n}=1$ for each matrix). Since at all instances the measured GHB concentration was within $\pm 15 \%$ of the nominal value, we concluded that no interference with the GHB determination was seen. Also the possible interference by common drugs of abuse, such as ketamine, flunitrazepam, amphetamine, 3,4-methylenedioxy- $\mathrm{N}$ methylamphetamine (MDMA), cocaine, benzoylecgonine, tetrahydrocannabinol (THC), 11-nor-9-carboxy-THC, and ethanol was evaluated. Therefore, $100 \mu \mathrm{l}$ spiked urine $(10 \mu \mathrm{g} / \mathrm{ml} \mathrm{GHB})$, plasma (5 $\mu \mathrm{g} / \mathrm{ml} \mathrm{GHB})$ and whole blood ( $5 \mu \mathrm{g} / \mathrm{ml} \mathrm{GHB}$ ) samples containing these interferences in concentrations above therapeutic or toxic range 
were analyzed ( $n=1$ for each matrix). Also here, GHB measurements were within $\pm 15 \%$ of the nominal value in all cases, meaning that there was no interference with the GHB determination.

Since derivatization occurs in an alkaline environment, reported to favour hydrolysis of the lactone GBL to GHB in aqueous matrices [28], samples were spiked at $100 \mu \mathrm{g} / \mathrm{ml} \mathrm{GBL}(\mathrm{n}=6)$ to evaluate GBL-GHB conversion. $109 \pm$ $3.3 \mu \mathrm{g} / \mathrm{ml} \mathrm{GHB}$ was measured in the urine samples, $111 \pm 7.0 \mu \mathrm{g} / \mathrm{ml} \mathrm{GHB}$ in the plasma samples, $103 \pm 9.0$ $\mu \mathrm{g} / \mathrm{ml} \mathrm{GHB}$ in the serum samples, $113 \pm 4.9 \mu \mathrm{g} / \mathrm{ml} \mathrm{GHB}$ in the whole blood samples, and finally $98 \pm 12.0 \mu \mathrm{g} / \mathrm{ml}$ GHB in the lyzed blood samples, meaning that GBL had been completely converted to GHB during analysis. Therefore, this method determines total $\mathrm{GHB}(\mathrm{GHB}+\mathrm{GBL})$ in biofluids. Since $\mathrm{GBL}$ is converted to GHB within minutes after oral ingestion, GHB is the analyte of choice to search for in samples collected from suspected GBL/GHB-intoxicated patients [17,29,30].

\subsubsection{Linearity, precision, accuracy, dilution integrity and sensitivity}

To evaluate the calibration model for determining GHB in $100 \mu$ l of biofluid using HS-trap, in total 8 curves were constructed in the different biofluids, by preparing and analyzing on 4 different days, a blank (non-spiked), a zero (blank + IS) and $2 \times 9$ calibrators $(2,5,10,25,50,100,150,200$ and $250 \mu \mathrm{g} / \mathrm{ml} \mathrm{GHB}$ in urine and plasma; 2, $3.5,5,10,25,50,100,150$ and $200 \mu \mathrm{g} / \mathrm{ml}$ GHB in whole blood). Only for urine samples, calibrator ratios were lowered with the blank signal (ratio GHB/GHB-d6) and the calibration curve was found to be linear (using Fisher's test) from 2 to $150 \mu \mathrm{g} / \mathrm{ml} \mathrm{GHB}$. A working range of 5 to $150 \mu \mathrm{g} / \mathrm{ml}$ was selected for accuracy and precision experiments. The latter range includes the proposed cut-off level for GHB in urine (6 or $10 \mu \mathrm{g} / \mathrm{ml}$ ) [3134] and can be extended to $1500 \mu \mathrm{g} / \mathrm{ml}$ using a 10-fold dilution technique. Fig. 5 shows representative chromatograms of a blank and zero urine sample, as well as of a urine sample spiked at LLOQ. For plasma samples, the calibration curve was also found to be linear from 2 to $150 \mu \mathrm{g} / \mathrm{ml}$, and this range was also selected as working range (using the following 6 calibrators: 2, 5, 25, 50, 100 and $150 \mu \mathrm{g} / \mathrm{ml}$ ). Furthermore, the calibration curve was linear from 2 to $200 \mu \mathrm{g} / \mathrm{ml}$ GHB for whole blood samples, and a working range of 3.5 to $200 \mu \mathrm{g} / \mathrm{ml}$ was chosen (using the following 6 calibrators: 3.5, 10, 50, 100, 150 and $200 \mu \mathrm{g} / \mathrm{ml}$ ). The lower limit of this range is below the proposed cut-off level for GHB in blood, 4 or $5 \mu \mathrm{g} / \mathrm{ml}$, used to distinguish between endo- and exogenous GHB [33-34]. Upon evaluation of the resulting data, heteroscedasticity was observed in all matrices and $1 / x^{2}$ was chosen as weighting factor for urine and plasma, while for whole blood $1 / y^{2}$ was 
chosen. As shown in Table 2, where calibration, sensitivity, precision and accuracy data are summarized, requirements were fulfilled for all QC samples, prepared in the different biofluids and analyzed using the method described above. Importantly, the results for the QC's prepared in serum and lyzed blood demonstrate that calibration curves prepared in respectively plasma and whole blood can be used for quantification in these matrices.

As to method sensitivity, as mentioned above, no blank (GHB-free) matrices are available. Therefore, the lower limit of quantification was arbitrarily set at the lowest point of the calibration curve $(5 \mu \mathrm{g} / \mathrm{ml}$ for urine, $2 \mu \mathrm{g} / \mathrm{ml}$ for plasma and serum, and $3.5 \mu \mathrm{g} / \mathrm{ml}$ for whole blood). Samples with a GHB concentration above the upper limit of quantification can be diluted 10-fold with ultrapure water and in the case of plasma, serum and whole blood, also with non-spiked matrix, and can be analyzed as described above with acceptable precision and accuracy (see Table 2, QC 2 × ULOQ).

\subsubsection{Processed sample stability}

Low and high QC samples prepared in the different matrices, with all reagents added in a closed vial, were stored for at least $24 \mathrm{~h}$ at RT and for one week at $4{ }^{\circ} \mathrm{C}(\mathrm{n}=3)$. The measured GHB concentration was within $15 \%$ deviation from the original concentration in all cases. Thus, processed samples are stable under these storage conditions (Table 3), which further contributes to the convenience of the developed procedure.

\subsection{Application}

The applicability of the validated method using HS-trap as injection technique in combination with GC-MS for the determination of GHB in patient samples was demonstrated by analyzing 5 urine, 5 serum, and 1 whole blood sample collected from suspected GHB-intoxicated patients. An aliquot of the sample was also analyzed using the method of Van hee et al. [12]. Results are summarized in Table 4. Both the initial concentration and the concentration obtained by reanalysis using our described method varied from -4 to $4 \%$ from their mean, well in line with the above mentioned requirement for ISR. Furthermore, analyzing the study samples by the use of HS-trap and by the use of the method by Van hee et al. [12] led to similar GHB concentrations for the same sample. The difference between the two obtained results was within -9.4 to $16.7 \%$ from the mean, calculated by dividing the difference between the two results (separately obtained by the two above- 
mentioned methods for the same sample), by the mean of those two results and multiplying this division with 100. 


\section{Conclusion}

In the study presented here, "in-vial" derivatization and HS-trap injection are combined into an application with minimal hands-on time. This combination has resulted in a simple and accurate GC-MS method for determination of total GHB (GHB+GBL) in urine, plasma, serum, whole blood and lyzed blood. In contrast to other published methods, no extra sample pretreatment step is required for quantitative determination of GHB in e.g. blood: the same procedure can be applied to all biofluids, which can simply be added to the HS vial together with the reagents, followed by closure of the vial. Moreover, the fact that these samples can be stored for at least $24 \mathrm{~h}$ at RT or 7 days at $4{ }^{\circ} \mathrm{C}$ further adds to the convenience of the procedure. Besides the simplicity of the sample preparation, requiring a minimum of technical time, an important reduction of sample volume was accomplished in comparison to other HS-based methods, as a result of the trap and its associated gain in sensitivity. A sample volume of only $100 \mu \mathrm{l}$ is used, which is markedly lower than previously reported HS-based methods for GHB determination, which require 0.5 to $1 \mathrm{ml}$ sample volume. In conclusion, the use of HS-trap as injection technique results in a quick, simple and universal sample preparation protocol, only including the addition of salt and derivatization reagents directly to a given biological matrix. The method was shown to be selective and sensitive enough to quantify GHB in samples collected from suspected GHBintoxicated patients with LLOQ's below the proposed cut-off levels. In addition, incurred sample reanalysis demonstrated good assay reproducibility, while cross-validation with another method demonstrated comparable results. Furthermore, according to preliminary experiments, this method shows great potential to determine other compounds of interest in emergency toxicology or post-mortem cases, such as GBL itself, as well as 1,4-BD, beta-hydroxybutyric acid, diethylene glycol, glycolic acid and ethylene glycol, derivatized to their corresponding (di)-methyl derivatives.

\section{Acknowledgements}

We would like to thank Danielle Borrey and Alain Verstraete for their kind donation of GHB-positive (leftover and anonymous) samples and the volunteers who kindly donated whole blood and urine for method development and validation. 


\section{References}

[1] R.M. Smith, J. Chrom. A. 1000 (2003) 3.

[2] S.M. Wille, W.E. Lambert, Anal. Bioanal. Chem. 388 (2007) 1381.

[3] B.T. Røen, E. Unneberg, J.Aa. Tørnes, E. Lundanes, J. Chrom. A. 1217 (2010) 761.

[4] K. Schulz, J. Dreßler, E.M. Sohnius, D.W. Lachenmeier, J. Chrom. A. 1145 (2007) 204.

[5] B.T. Røen, E. Unneberg, J.Aa. Tørnes, E. Lundanes, J. Chrom. A. 1217 (2010) 2171.

[6] M.P. Nikfardjam, D.Maier, Food Chem. 126 (2011) 1926.

[7] A. Aberl, M. Coelhan, J. Agric. Food Chem. 60 (2012) 2785.

[8] D.L. Zvosec, S.W. Smith, T. Porrata, A.Q. Strobl, J.E. Dyer, Am. J. Emerg. Med. 29(3) (2011) 319.

[9] J.G.C. Van Amsterdam, T.M. Brunt, M.T.B. McMaster, R.J.M. Niesink, Neurosci. Biobehav. Rev. 36 (2012) 1217.

[10] S.R. Dahl, K.M. Olsen, D.H. Strand, J. Chrom. B, 885-886 (2012) 37.

[11] C.L. Morris-Kukoski, Toxicol. Rev. 23 (2004) 33.

[12] P. Van hee, H. Neels, M. De Doncker, N. Vrydags, K. Schatteman, W. Uyttenbroeck, N. Hamers, D. Himpe, W. E. Lambert, Clin. Chem. Lab. Med. 42 (2004) 1341.

[13] M.R. Meyer, A.A. Weber, H.H. Maurer, Anal. Bioanal. Chem. 400 (2011) 411.

[14] A.S. Ingels, W.E. Lambert, C.P. Stove, Anal. Bioanal. Chem. 398 (2010) 2173.

[15] A.S. Ingels, P. De Paepe, K. Anseeuw, D. Van Sassenbroeck, H. Neels, W. Lambert, C. Stove, Bioanalysis 3 (2011) 2271. [16] M.A. LeBeau, M.A. Montgomery, M.L. Miller, S.G. Burmeister, J. Anal. Tox. 24 (2000) 421.

[17] G. Frison, L. Tedeschi, S. Maietti, S.D. Ferrara, Rapid Com. Mass Spectr. 14 (2000) 2401.

[18] D. Lenz, L. Kröner, M.A. Rothschild, J. Chrom. A 1216 (2009) 4090. 
[19] S. Blair, M. Song, B. Hall, J. Brodbelt, J. Forensic Sci. 46 (2001) 688.

[20] S.D. Brown, D.J. Rhodes, B.J. Pritchard, Forensic Sci. Int. 171 (2007) 142.

[21] S.D. Harvey, J.H. Wahl, J. Chrom. A 1256 (2012) 58.

[22] F. Barani, N. Dell’Amico, L. Griffone, M. Santoro, C. Tarabella, J. Chromatogr. Sci. 44 (2006) 625.

[23] I. Rasanen, J. Viinamäki, E. Vuori, I. Ojanperä, J. Anal. Tox. 34 (2010) 113.

[24] B. Kolb, L.S. Ettre, Static headspace - gas chromatography: theory and practice, John Wiley and sons inc., Hoboken, New Jersey, $2^{\text {nd }}$ edition, 2006.

[25] EMA Guideline on bioanalytical method validation, Committee for Medicinal Products for Human Use (CHMP), 21 July 2011.

http://www.ema.europa.eu/docs/en GB/document library/Scientific guideline/2011/08/WC500109686.pdf

[26] S.M.R. Wille, F.T. Peters, V. Di Fazio, N. Samyn, Accred. Qual. Assur. 16 (2011) 279.

[27] M.J. Cardador, M. Gallego, Anal. Bioanal. Chem. 396 (2010) 1331.

[28] L.A. Ciolini, M.Z. Mesmer, R.D. Satzger, A.C. Machal, H.A. McCauley, A.S. Mohrhaus, J. Forensic Sci. 46 (2001) 1315.

[29] D.M. Roberts, M.W. Smith, M. Gopalakrishnan, G. Whittaker, R.O. Day, Ann. Emerg. Med. 58(1) (2011) 83.

[30] S.P. Elliott, Ther. Drug Monit. 26(4) (2004) 432.

[31] H. Andresen, N. Sprys, A. Schmoldt, A. Mueller, S. Iwersen-Bergmann, For. Sci. Int. 200 (2010) 93.

[32] M.A. LeBeau, M.A. Montgomery, For. Sci. Int. 207 (2011) e61.

[33] A.A. Elian, For. Sci. Int. 128 (2002) 120.

[34] S.P. Elliott, For. Sci. Int. 133 (2003) 9. 


\section{Highlights}

HS-trap GC-MS is used to determine GHB in biofluids using "in-vial" derivatization.

We add only $100 \mu \mathrm{l}$ sample, salt and methylation reagent to a single headspace vial.

Combining "in-vial" methylation with HS-trap allows for minimal hands-on time.

Acceptable method precision, accuracy and sensitivity are observed.

Cross-validation demonstrates the suitability in routine toxicological analysis. 
Table 1 Evaluated HS and trap settings for the determination of GHB in $100 \mu$ urine, serum, plasma and whole blood samples $(22 \mathrm{ml}$ vial) using "in-vial" derivatization and GC-MS. Underlined values indicate the initially tested settings; bold values indicate the optimal settings chosen for the final method.

\begin{tabular}{|c|c|c|c|c|c|}
\hline \multicolumn{6}{|c|}{ Headspace conditions } \\
\hline $\begin{array}{l}\text { Oven temperature: } \\
70-90{ }^{\circ} \mathrm{C} \\
\text { Needle temperature: } \\
\underline{95^{\circ} \mathrm{C}}\end{array}$ & $\begin{array}{l}90^{\circ} \mathrm{C} \\
95^{\circ} \mathrm{C}\end{array}$ & $\begin{array}{l}\text { Thermostat time: } \\
\text { 10-20-25-30-45-60 min } \\
\text { Vial pressurization time: } \\
\text { 1-2-3 min } \\
\text { Decay time*: } \\
0.8-1.2-1.4 \mathrm{~min}\end{array}$ & $\begin{array}{l}30 \mathrm{~min} \\
1 \mathrm{~min} \\
1.2 \mathrm{~min}\end{array}$ & $\begin{array}{l}\text { Column pressure: } \\
\qquad \underline{15} \text { psi } \\
\text { Vial pressure: } \\
\underline{20-25-30-35 ~ p s i}\end{array}$ & $\begin{array}{l}15 \text { psi } \\
30 \text { psi }\end{array}$ \\
\hline \multicolumn{6}{|c|}{ Trap settings } \\
\hline $\begin{array}{l}\text { Trap low temperature: } \\
\text { 40-50-55 }{ }^{\circ} \mathrm{C} \\
\text { Trap high temperature: } \\
245-\underline{250}-265-275^{\circ} \mathrm{C}\end{array}$ & $50^{\circ} \mathrm{C}$ & $\begin{array}{l}\text { Dry purge time: } \\
\underline{5}-7.5-10 \mathrm{~min} \\
\text { Desorption time: } \\
\underline{0.5}-2-10 \mathrm{~min} \\
\text { Trap hold time: } \\
\underline{5}-8-10 \mathrm{~min}\end{array}$ & $\begin{array}{l}10 \mathrm{~min} \\
2 \mathrm{~min} \\
10 \mathrm{~min}\end{array}$ & $\begin{array}{l}\text { Desorption pressure } \\
\underline{20}-25-30-35 \text { psi }\end{array}$ & 30 psi \\
\hline
\end{tabular}

* Decay time= Trap load time

$\$$ Desorption pressure= Dry purge pressure 
Table 2

Sensitivity and calibration data: HS-trap GC- MS analysis of $100 \mu$ l of urine, plasma or whole blood samples using "in vial" derivatization

\begin{tabular}{|l|c|c|c|c|c|c|}
\hline & $\begin{array}{c}\text { Slope } \\
( \pm \mathrm{SD} ; 95 \% \mathrm{Cl}) \\
(\mathrm{n}=4 \times 2)\end{array}$ & $\begin{array}{c}\text { Intercept } \\
( \pm \mathrm{SD} ; 95 \% \mathrm{Cl}) \\
(\mathrm{n}=4 \times 2)\end{array}$ & $\begin{array}{c}\text { R square } \\
(\mathrm{n}=4 \times 2)\end{array}$ & $\begin{array}{c}\text { LLOQ } \\
(\mu \mathrm{g} / \mathrm{ml})\end{array}$ & $\begin{array}{c}\text { Working } \\
\text { range } \\
(\mu \mathrm{g} / \mathrm{ml})\end{array}$ & $\begin{array}{c}\text { Weighting } \\
\text { factor }\end{array}$ \\
\hline Urine & $0.0505 \pm 0.005$ & $\begin{array}{c}0.0178 \pm 0.0306 \\
(0.0470 ; 0.0539)\end{array}$ & 0.999 & 5.0 & $5.0-150$ & $1 / \mathrm{x}^{2}$ \\
\hline Plasma & $0.0477 \pm 0.002$ & $\begin{array}{c}0.0035 \pm 0.0107 \\
(-0.004 ; 0.0110)\end{array}$ & 0.996 & 2.0 & $2.0-150$ & $1 / \mathrm{x}^{2}$ \\
\hline Whole blood & $(0.0461 ; 0.0493)$ & & & & \\
& $0.0420 \pm 0.003$ & $\begin{array}{c}0.0063 \pm 0.0066 \\
(0.0398 ; 0.0442)\end{array}$ & 1.000 & 3.5 & $3.5-200$ & $1 / \mathrm{y}^{2}$ \\
\hline
\end{tabular}

Precision and accuracy data of the quality control samples (100 $\mu$ l urine, plasma, serum, whole and lyzed blood) analyzed with HS-trap GC-MS in combination with "in vial" derivatization ( $n=4 \times 2$ ).

\begin{tabular}{|c|c|c|c|c|c|}
\hline & $\begin{array}{l}\text { Nominal GHB } \\
\text { concentration } \\
(\mu \mathrm{g} / \mathrm{ml})\end{array}$ & $\begin{array}{l}\text { Measured GHB } \\
\text { concentration } \\
(\mu \mathrm{g} / \mathrm{ml})\end{array}$ & $\begin{array}{l}\text { Intra-batch } \\
\text { precision } \\
\text { (\% RSD) }\end{array}$ & $\begin{array}{l}\text { Inter-batch } \\
\text { precision } \\
\text { (\% RSD) }\end{array}$ & $\begin{array}{l}\text { Accuracy } \\
\text { (Bias \%) }\end{array}$ \\
\hline \multicolumn{6}{|l|}{ Urine } \\
\hline LLOQ & 5 & 4.7 & 1.3 & 9.6 & -6.7 \\
\hline QC low & 10 & 9.9 & 3.1 & 4.6 & -1.4 \\
\hline QC medium & 75 & 71.9 & 1.9 & 6.1 & -4.1 \\
\hline QC high & 125 & 125.4 & 8.5 & 12.6 & 0.3 \\
\hline $2 \times$ ULOQ & 300 & 296.1 & 1.5 & 4.6 & -1.3 \\
\hline \multicolumn{6}{|l|}{ Plasma } \\
\hline LLOQ & 2 & 1.8 & 4.3 & 9.9 & -10.4 \\
\hline QC low & 5 & 5.0 & 3.5 & 8.9 & 0.1 \\
\hline $\mathrm{QC}$ medium & 75 & 67.5 & 2.1 & 4.3 & -10.0 \\
\hline QC high & 125 & 117.0 & 0.5 & 6.4 & -6.4 \\
\hline $2 \times$ ULOQ & 300 & 273.1 & 2.9 & 5.4 & -9.0 \\
\hline $\begin{array}{l}2 \times \text { ULOQ } \\
(\text { matrix) }\end{array}$ & 300 & 310.8 & 5.6 & 11.0 & 3.6 \\
\hline \multicolumn{6}{|l|}{ Serum } \\
\hline LLOQ & 2 & 1.8 & 4.4 & 10.6 & -9.2 \\
\hline QC low & 5 & 4.9 & 2.3 & 9.0 & -1.1 \\
\hline QC medium & 75 & 69.4 & 2.3 & 8.5 & -7.5 \\
\hline QC high & 125 & 114.1 & 3.6 & 5.2 & -8.7 \\
\hline $2 \times$ ULOQ & 300 & 266.6 & 3.3 & 4.7 & -11.2 \\
\hline $2 \times$ ULOQ & 300 & 313.6 & 4.6 & 8.4 & 4.5 \\
\hline
\end{tabular}




\begin{tabular}{|c|c|c|c|c|c|}
\hline$(\text { matrix })^{a}$ & & & & & \\
\hline \multicolumn{6}{|l|}{ Whole blood } \\
\hline LLOQ & 3.5 & 3.4 & 4.3 & 11.8 & -1.7 \\
\hline QC low & 7.5 & 7.8 & 3.9 & 4.7 & 4.3 \\
\hline QC medium & 75 & 75.8 & 4.9 & 7.8 & 1.0 \\
\hline QC high & 160 & 158.3 & 5.0 & 7.6 & -1.1 \\
\hline $2 \times$ ULOQ & 400 & 360.0 & 3.3 & 9.5 & -10.0 \\
\hline $\begin{array}{l}2 \times \cup L O Q \\
(\text { matrix })^{a}\end{array}$ & 400 & 388.3 & 4.5 & 11.1 & -2.9 \\
\hline \multicolumn{6}{|l|}{ Lyzed blood } \\
\hline LLOQ & 3.5 & $3.9^{b}$ & $6.4^{b}$ & $7.7^{b}$ & $10.4^{b}$ \\
\hline QC low & 7.5 & 7.8 & 4.5 & 6.6 & 4.2 \\
\hline QC medium & 75 & 71.6 & 6.7 & 8.2 & -4.6 \\
\hline QC high & 160 & 159.8 & 6.4 & 8.6 & -0.1 \\
\hline $2 \times$ ULOQ & 400 & 375.0 & 6.1 & 10.3 & -6.3 \\
\hline $\begin{array}{l}2 \times \text { ULOQ } \\
\left(^{\text {matrix })^{a}}\right.\end{array}$ & 400 & 379.3 & 2.8 & 8.2 & -5.2 \\
\hline
\end{tabular}

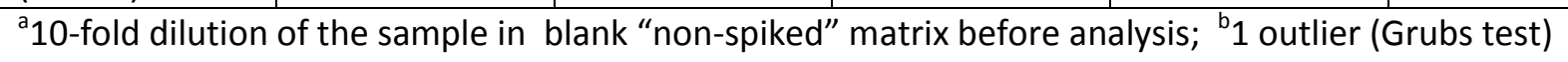


Table 3 Processed sample stability: The average \% deviation from the original concentration $\left(T_{0}\right)$ is given for low and high processed QC samples $(n=3)$ stored for at least $24 \mathrm{~h}$ at room temperature and for at least 7 days at $4{ }^{\circ} \mathrm{C}$.

\begin{tabular}{|c|c|c|c|}
\hline LOW QC & $\begin{array}{c}\text { Nominal } \\
\text { GHB conc } \\
(\mu \mathrm{g} / \mathrm{ml})\end{array}$ & $\begin{array}{c}\text { Room temperature } \\
24 \mathrm{~h}\end{array}$ & $\begin{array}{c}4{ }^{\circ} \mathrm{C} \\
\text { days }\end{array}$ \\
\hline urine & 10 & $\begin{array}{c}\text { \% deviation from } \mathrm{T}_{0} \\
\text { concentration }\end{array}$ & $\begin{array}{c}\text { \% deviation from } \mathrm{T}_{0} \\
\text { concentration }\end{array}$ \\
\hline plasma & 5 & 2.2 & 0.6 \\
\hline serum & 5 & 1.7 & -12.4 \\
\hline whole blood & 7.5 & 13.9 & -14.8 \\
\hline lyzed blood & 7.5 & 7.2 & -9.1 \\
\hline HIGH QC & & 7.0 & -5.1 \\
\hline urine & 125 & & -4.1 \\
\hline plasma & 125 & -0.5 & -6.3 \\
\hline serum & 125 & -8.2 & -0.7 \\
\hline whole blood & 160 & 1.8 & -12.2 \\
\hline lyzed blood & 160 & 13.7 & -10.8 \\
\hline
\end{tabular}


Table 4 Measured GHB concentrations $(\mu \mathrm{g} / \mathrm{ml})$ in real samples using the HS-trap GC-MS method (HS-trap) and the method of Van hee et al. [12]. Urine samples (U) were frozen at $-20^{\circ} \mathrm{C}$ before reanalysis after 14 days; serum (S) samples were frozen at $-20{ }^{\circ} \mathrm{C}$ before reanalysis after 30 days; whole blood sample was frozen at $-20^{\circ} \mathrm{C}$ before reanalysis after 7 days.

\begin{tabular}{|c|c|c|c|}
\hline & \multicolumn{3}{|c|}{ GHB conc $(\mu \mathrm{g} / \mathrm{ml})$} \\
\hline sample & HS-trap & HS-trap (ISR) & Van hee et al. \\
\hline U1 & 546 & 555 & 600 \\
\hline U2 & 991 & 1024 & 1052 \\
\hline U3 & 385 & 393 & 587 \\
\hline U4 & 58 & 59 & 531 \\
\hline U5 & 596 & 587 & 11 \\
\hline S1 & 13 & 12 & 69 \\
\hline S2 & 70 & 68 & 134 \\
\hline S3 & 128 & 124 & 224 \\
\hline S4 & 259 & 247 & 220 \\
\hline S5 & 220 & 231 & 186 \\
\hline WB1 & 183 & 176 & \\
\hline
\end{tabular}




\section{Figure Captions}

Fig. 1 Optimization of the "in-vial" derivatization:

$\mathrm{NaOH} 5 \mathrm{M}$-solution and dimethylsulfate were added to $100 \mu \mathrm{l}$ urine, plasma and whole blood spiked with 25 $\mu \mathrm{g} / \mathrm{ml} \mathrm{GHB}$ in three different ratio's: 0.5:1.0, 1.0:1.0, 2.0:1.0 (v:v). Samples were analyzed using a HS-trap GCMS method and resulting peak areas of GHB for each ratio (mean $\pm S D ; n=3$ ) were plotted for each matrix.

Fig. 2 Effect of salting out:

To $100 \mu$ urine, plasma and whole blood, spiked with 10 (urine) or 25 (plasma and whole blood) $\mu \mathrm{g} / \mathrm{ml} \mathrm{GHB}$, varying amounts of anhydrous $\mathrm{Na}_{2} \mathrm{SO}_{4}$ were added (mg). Samples were analyzed using a HS-trap-GC-MS method. The resulting peak areas of $\mathrm{GHB}$ (mean $\pm \mathrm{SD} ; \mathrm{n}=3$ ) for the various amounts of salt added were plotted for each matrix.

Fig. 3 Time to reach equilibrium for GHB in $100 \mu \mathrm{l}$ urine, plasma and whole blood, spiked at $25 \mu \mathrm{g} / \mathrm{ml} \mathrm{GHB}$, at $90{ }^{\circ} \mathrm{C}$ without shaking: the peak areas of GHB (mean $\pm \mathrm{SD} ; \mathrm{n}=3$ ) are plotted in function of equilibration time for each matrix.

Fig. 4 Repeated vial extraction:

The peak areas of GHB (mean \pm SD; $n=3$ ) after one and two trap load cycles are plotted for $100 \mu$ l urine (spiked at $10 \mu \mathrm{g} / \mathrm{ml} \mathrm{GHB}$ ), plasma (spiked at $5 \mu \mathrm{g} / \mathrm{ml} \mathrm{GHB}$ ) and whole blood (spiked at $5 \mu \mathrm{g} / \mathrm{ml} \mathrm{GHB}$ ).

Fig. 5 Representative chromatograms of a blank (a), a zero (b) and a $5 \mu \mathrm{g} / \mathrm{ml}$-GHB-spiked (LLOQ) (c) urine sample. Mass spectrum in SCAN mode of di-methyl GHB (ions in bold are those followed by SIM), with indication of the fragmentation site for the quantifier ion (underlined) (d). 
Fig. 1

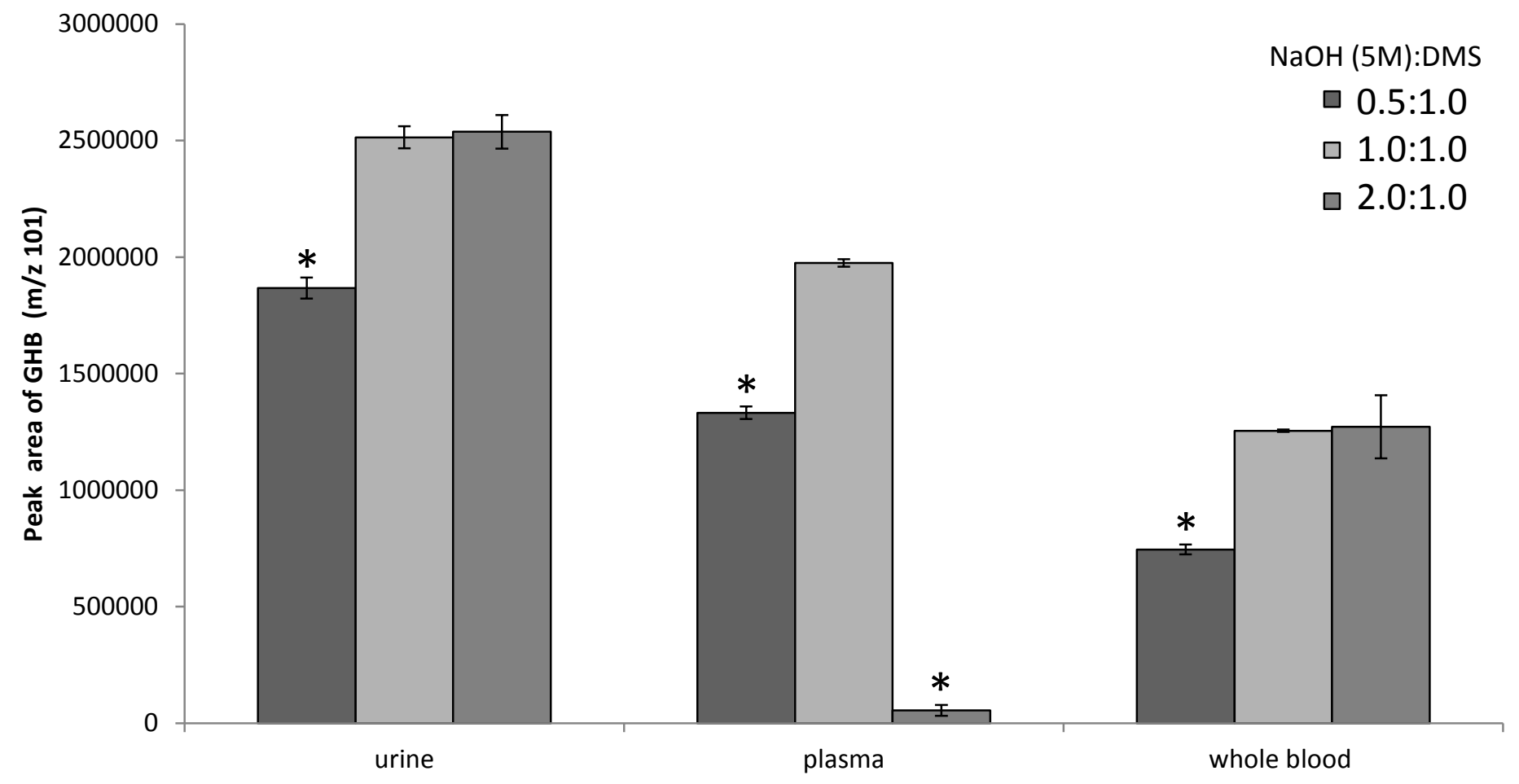

* significantly different, $\alpha=0.05, n=3$ 
Fig. 2

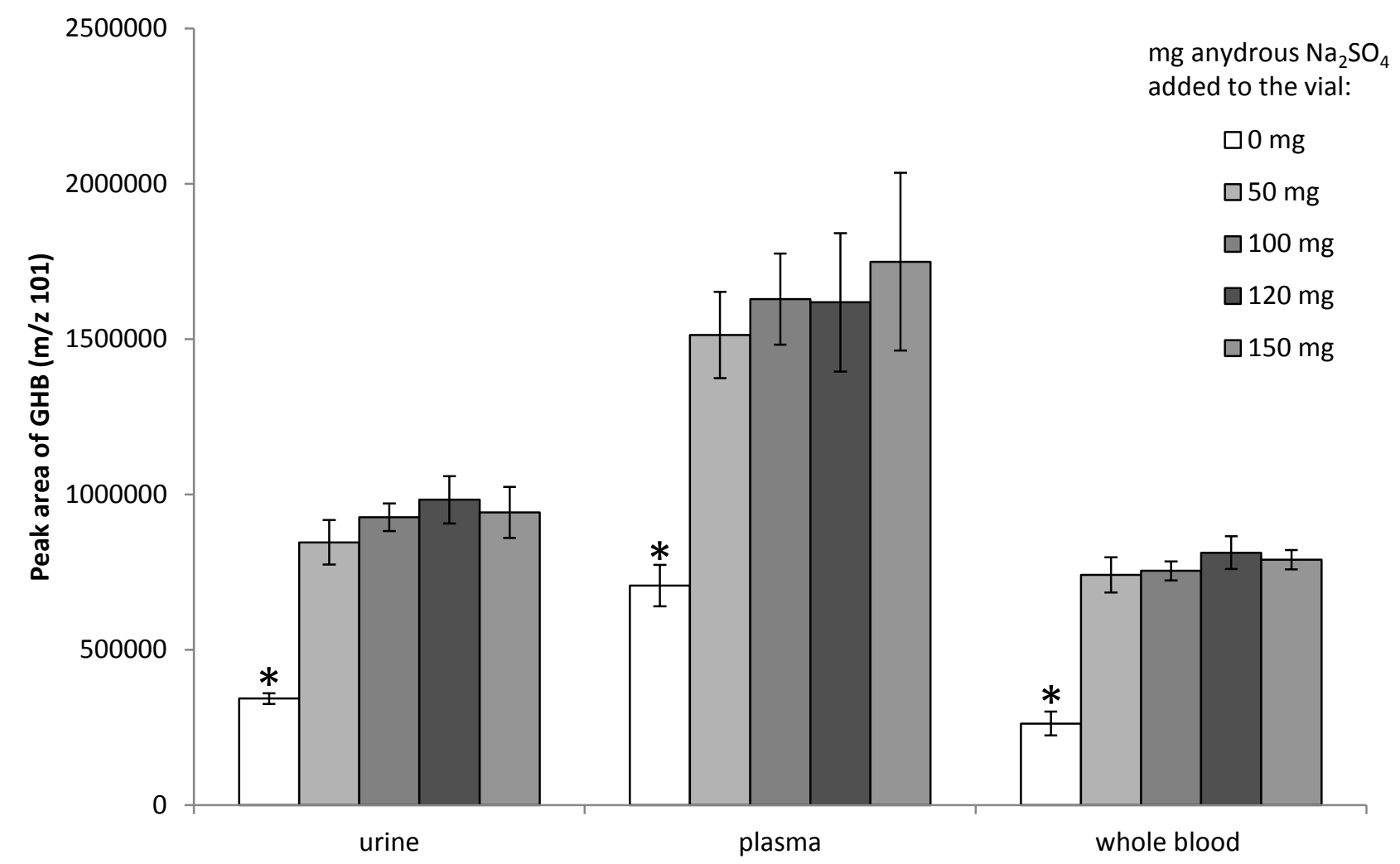

* Significantly different, $\alpha=0.05, n=3$ 
Fig. 3

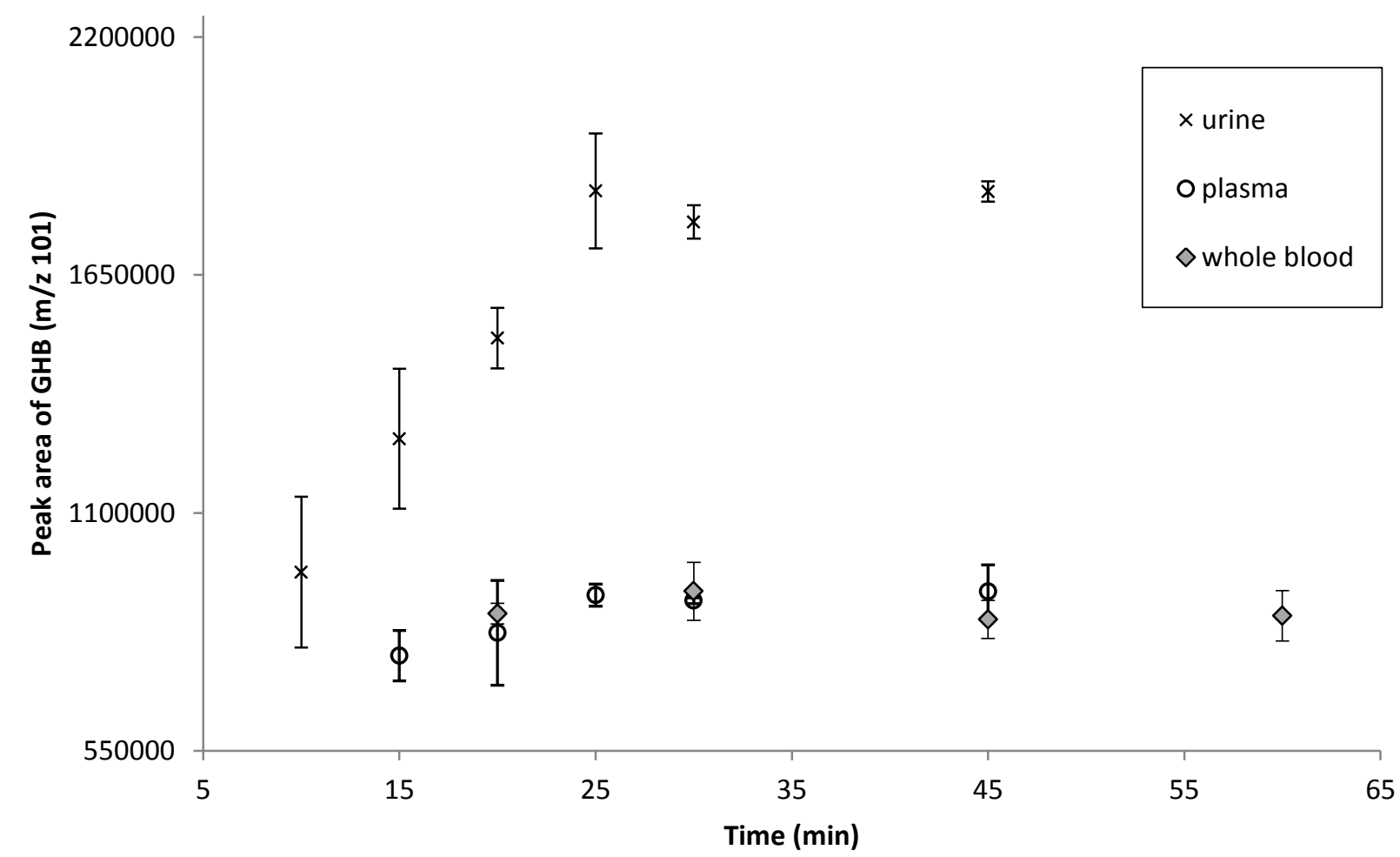


Fig. 4

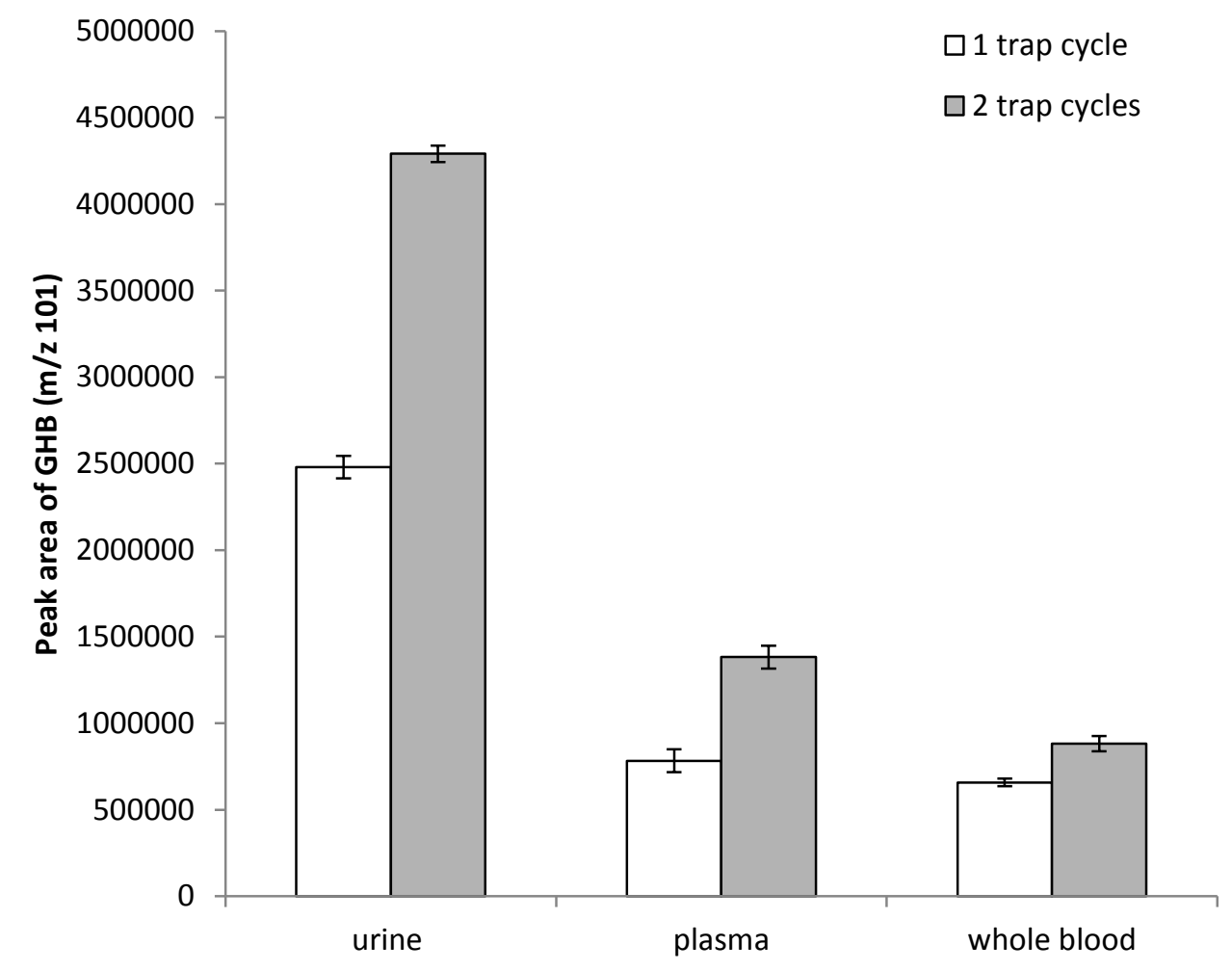


Fig. 5
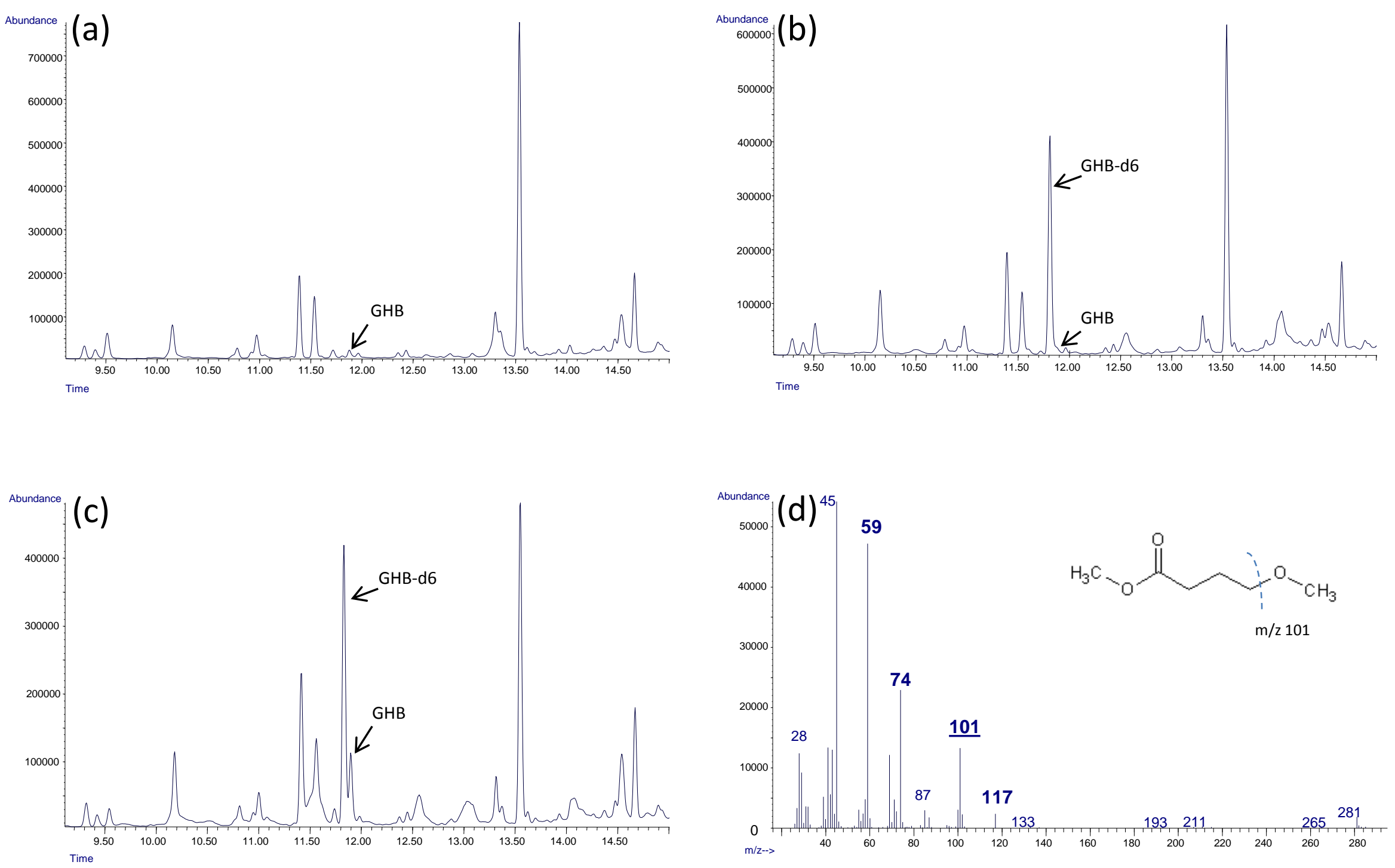
Supplementary file 1 Equilibration time required for GHB (spiked at $25 \mu \mathrm{g} / \mathrm{ml}$ ) in $100 \mu \mathrm{l}$ urine (a), plasma (b) and whole blood (c) samples in $22 \mathrm{ml} \mathrm{HS}$ vials at $90{ }^{\circ} \mathrm{C}$ with ( $\square$ ) and without (O) shaking during thermostatting $(n=3$, mean $\pm S D)$.
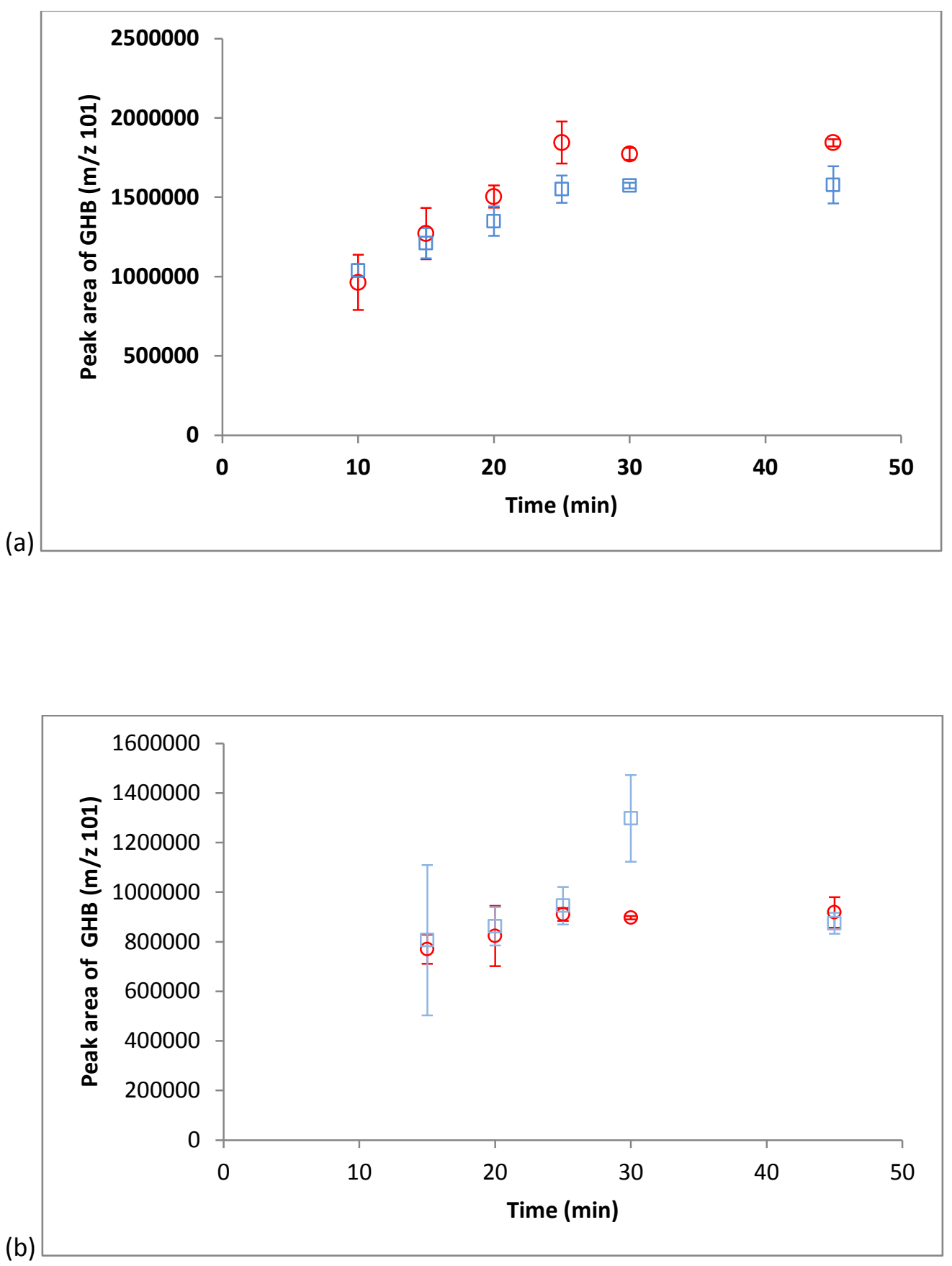


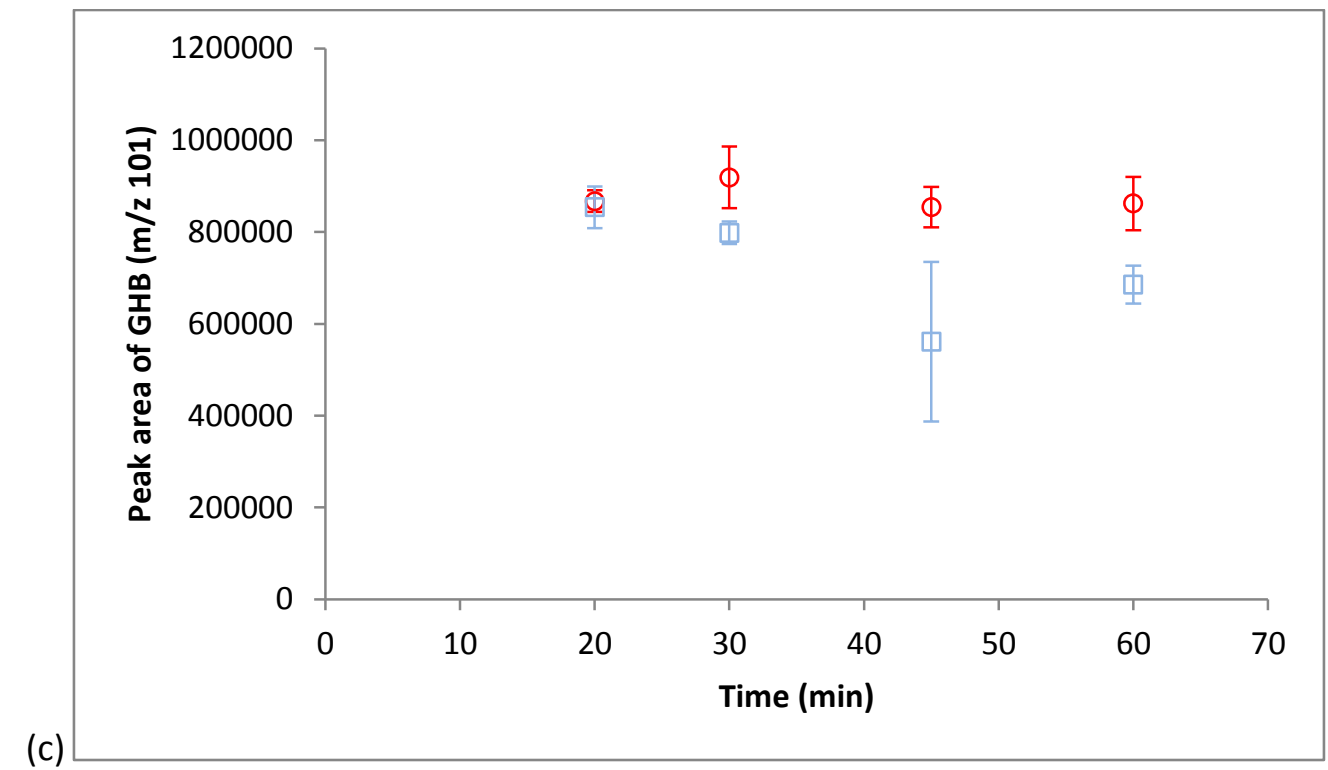

